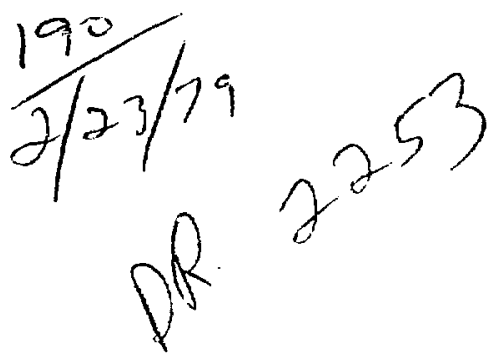

n

$\therefore$
LBL -8722

UC -37

\title{
ONE SHOTS AND ALTERNATIVES IN \\ SYNCHRONOUS DIGITAL SYSTEM DESIGN
}

Steve Hui and John B. Meng

$$
\text { January } 1979
$$

Prepared for the U. S. Department of Enercy under Contract $1 \mathrm{H}-7405-E N G-48$

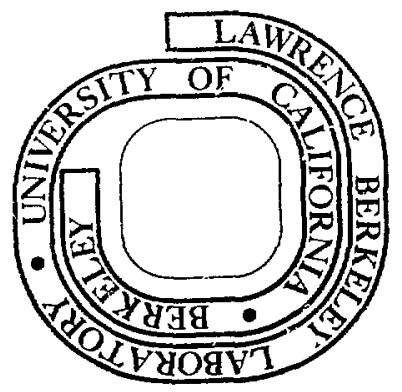


ONE SHOTS AND ALTERNATIVES IN SYNCHRONOUS DIGITAL SYSTEM DESIGN

Steve Hui \& John B. Meng

January 1979

Prepared for the U.S. Department of Energy under Contract $W-7405-E N G-48$ 
ONE SHOTS AND ALTERNATIVES IN SYNCHRONOUS DIGITAL SYSTEM DESIGN Steve Hui \& John D. Meng

The one shot or monostahle multivihrator is quite often regarded as a "black sheep" in ditigal integrated circuits. Its distinctions and versatility are well known and do not necessitate mentioning. Some of the potential problems with this black sheep are surmarized as follows:

1. A one shot may respond to glitches either on power supplies or on ground lines.

2. Noise pick up is a potential probiem. If the leads of the RC timing components are long, noise pick up will result in faultiy operation. An example is having a trimer of $\mathrm{RC}$ components mounted on the tront panel and the one shot on the printed circuit board a few inches away.

3. Faulty operation of a one shot is freguently not. a complete intearated circuit failure, such as sticking at one or zero. It is intermittent, making troubleshooting relatively difficult.

4. Incomplete triggerina has been observed. When the width of the triggering pulse narrows sufficiently, the output width may decrease drastica?ly out not disappear. There may be problems if the one shot's output pulse is used for driving more than one device. Detection of these problems are not easy. 
Even if technology eliminates all of the above problems, one shot.s still have the following undesirable features in digital systems:

1. In using a one shot, we potentially have the prohlem of having the pulse width too long or too short, requiring adjustment. Such trimming is undesirable in systems which must be mass reproduced

2. It is very convenient for Gehugging if one can step through a system's operation one clack oulse at a time. Such a single stepping scheme may not work with systems including one shots. For example, assume a system is malfuntioning at normal clock rate. Suppose the input to the one shot changes during the output pulse and the output pulse is extended. At a slow clock rate or with single step clocking, the condition causing such problems is not present anc the cause may not be identified. (If it is a fullv synchronous system, the time relationship between all signal changes and state changes remains unchanged in spite of the clock beina fast or slow. We can do sinqle step clocking).

3. As mentioned previously, a one shot's tailure is very likeiy not a sticking at one or zero, but today, fault detection and location are of ten based on sticking at one or zero. Consequently, implementation and automation of fault detection, fault recovery and correction are oriented towards this capability. Typical examples are 
(3)

diagnostic software and firmware for computer based systems and fully automatic fault location for digital systems. They check states of the machines but not the transients. (In a manual mode of fault location, logic analyzers can spot transierts).

4. A one shot is an asynchronous circuit. Placing a one shot in a synchronous circuit may destroy some of the virtues of heing synchronous. In a fully sylchronous circuit, circuit states only change on clock edges. During the time between these clock edges, the entire circuit remains unchanged, independent of the environment. That is, the circuit is immune to transients and noise except for the short time during clock edaes. Using one shots in a sunchronous circuit may eliminate this very desirable advantage.

The ahove is not to suagest complete elimination of one shots from our applications. The one shot is a useful device, an excellent choice for certain applications. In other apolications, particularly in sychronous diaital circuits, alternatives to one shots are worth considering. Some of these alternatives for synchronous circuits are offered and implemented below:

Replacement of Une Shots by Flip Flops and Gates in Synchronous

\section{Circuits}

A. Input triggers an output pulse of one clock period as in Figure 1. The input in Figure 1 must be synchronous with the circuit. and longer than one clock period for reliable 
operation. There is always one pulse generated for each time the input goes from low to high, regartless of the time the input stays high.

B. Input triggers an output pulse of two clock periods in Fiqure 2 and three clock periods in Figure 3. The conditions in A above also apply here.

C. Input triggers an output of four or more clock periods in Fiqure 4. The conditions in A above also apply here. The counter used in this scheme must be "synchronous load" and long output pulse widths can be achieved by cascading counters. Case $B$ can also use this method if cost is not a serious consideration.

D. Input triggers a delayed output pulse as in Figure 5. The delay and pulse width can he lencithened cascading counters. The conditions of case $A$ also apply here.

The ahove designs from Case $A$ to case $E$ are intended for fully snychronous circuits (preset and clear inputs are not used), making them applicable in hiqh speed application. The tolerance on nulse width generated is equal to the tolerance on clock rate. No trimming and adjustments are reguired

\section{Replacement of !ne Shots by Delay Lines}

Somplexity (number of connections) and requirements for synchronous inputs are disadvantages of the above approaches. Simplicity, asynchronous inputs, improved reliability and accuracy can he obtained at hiaher cost by using delay lines as shown in Fiqure 6 .

The input pulse width must be longer than the delay caused by the delay line. TTL, LSTTL and ECL delay lines are commercially 
(5)

available with excellent specificiations. Programable, multiple output (different delay times) delay lines are also available. Delay lines are expensive (about sio apiece) but are compact, reliable and excellent for accurate timing purposes. For example, timing in a dynamic memory is a good application for delay lines.

The delay line approach and the flip flop and counter approach can be combined or mixed to meet different cost, reliability, delay and pulse width requirements.

\section{Replacement of One Shot Functions with Other Methods}

If exactness of pulse width is not of importance while cost and simplicity are, the approaches in Figures 7 and 8 are handy. Care must he taken in choosing the capacitor value, uhich should be small. These approaches are suitable for generating pulses in the nanosecond ranqe.

Fiaure $a$ is an example of using a one shot integrated circuit (IC) not as a one shot. We utilize the schmidt trigger inside the IC and the RC components for generating a delay. 


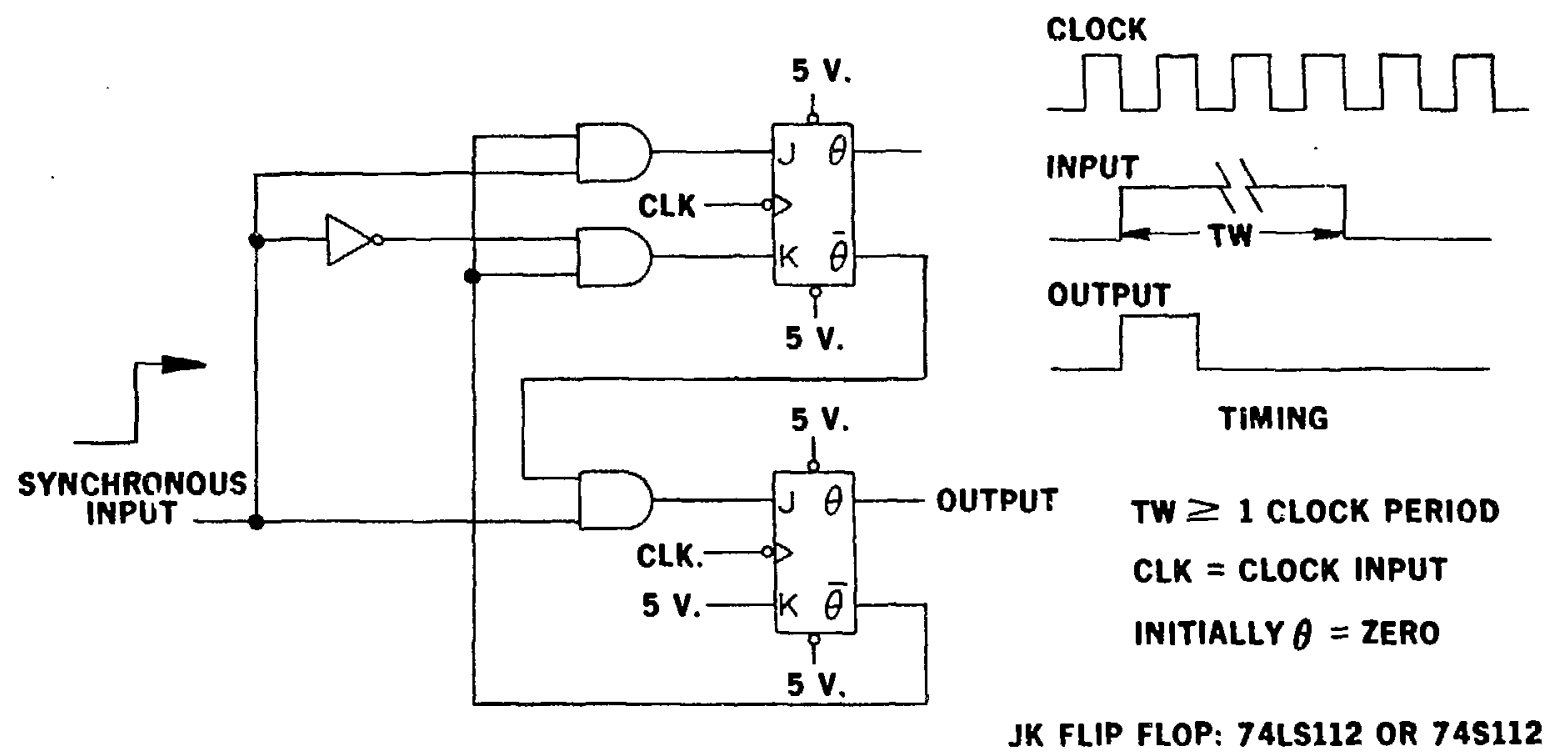

FIGURE - 1: INPUT TRIGGERS AN OUTPUT PULSE OF ONE CLOCK PERIOD 

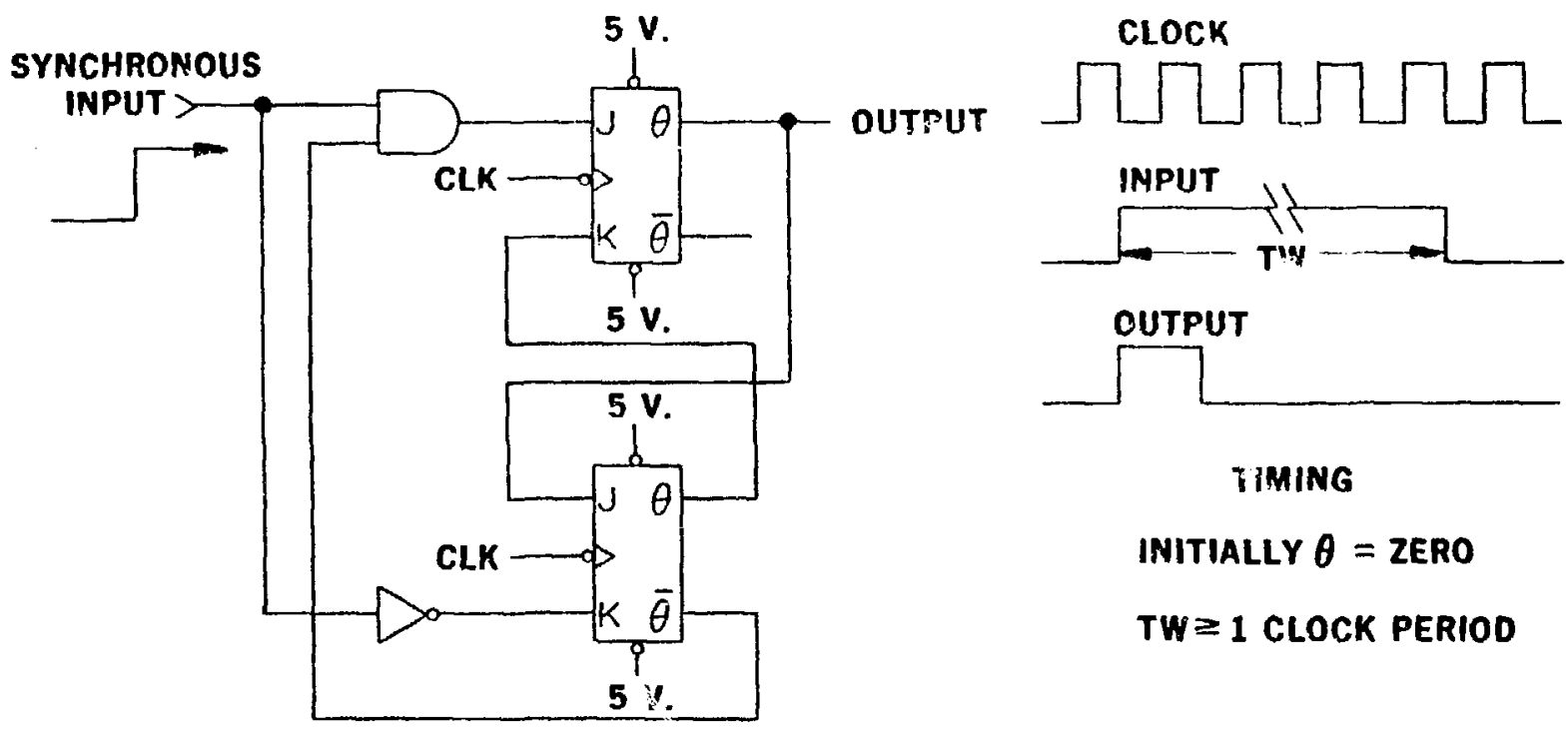

FIGURE - 2 : INPUT TRIGGERS AN OUTPUT PULSE OF TWO CLOCK PERIODS. 


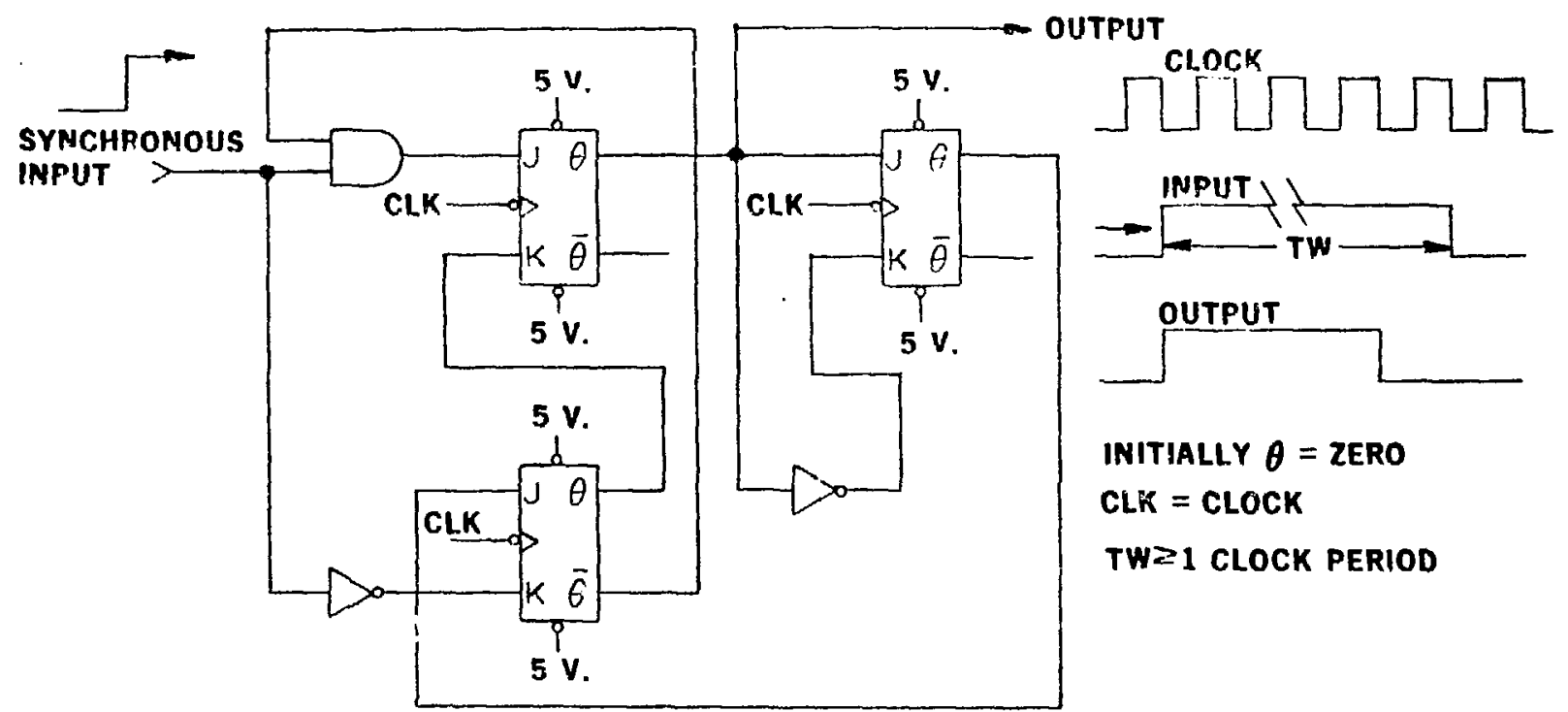




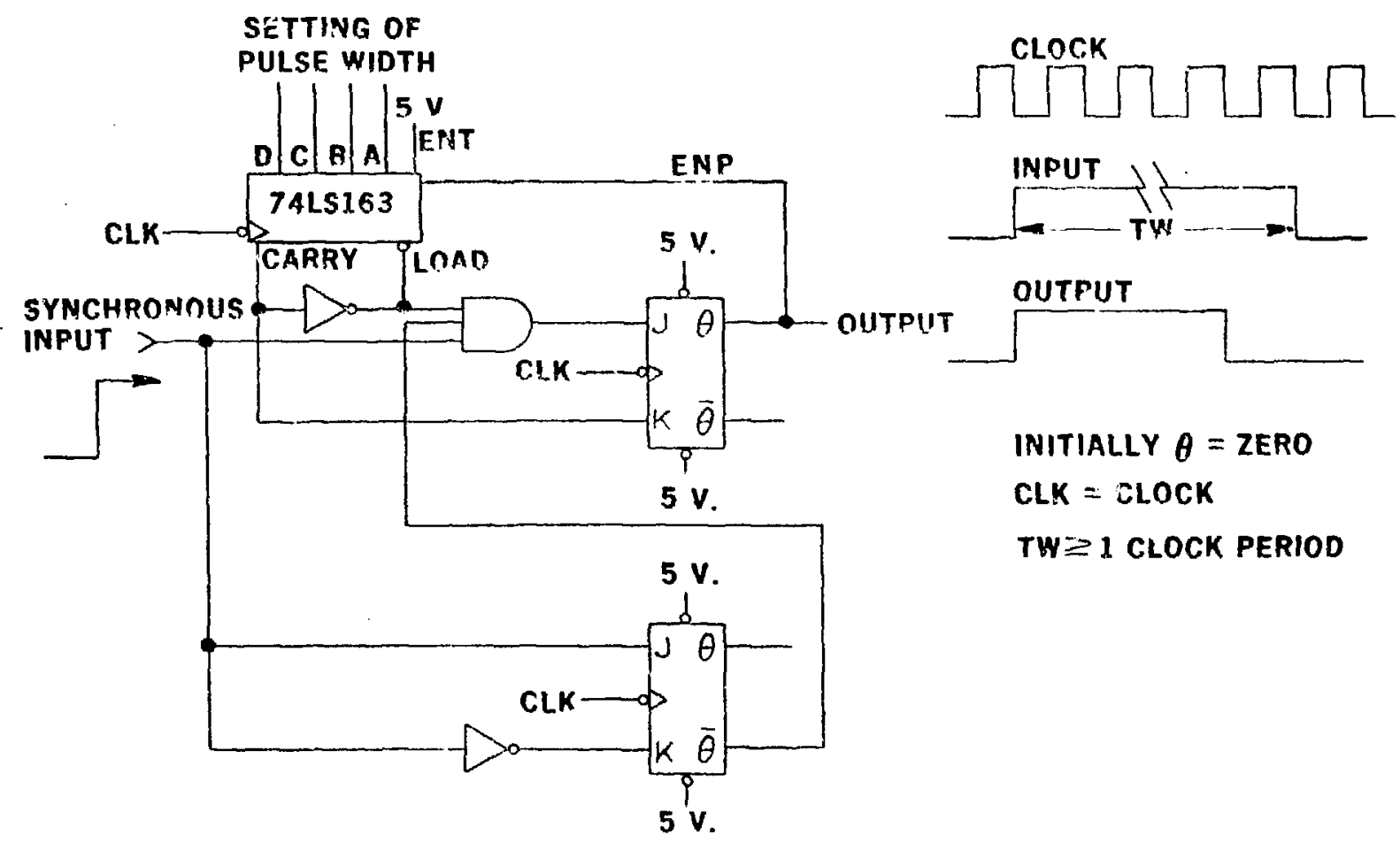

FIGURE - 4: INPUT TRIGGERS AN OUTPUT PULSE OF VARIABLE PULSE WIDTH 
FIGURE 5: INPUT TRIGGFRS MH OITTUT PILLSE MITH YAD!ARLE DCLAY AMD FILSE WIDTH

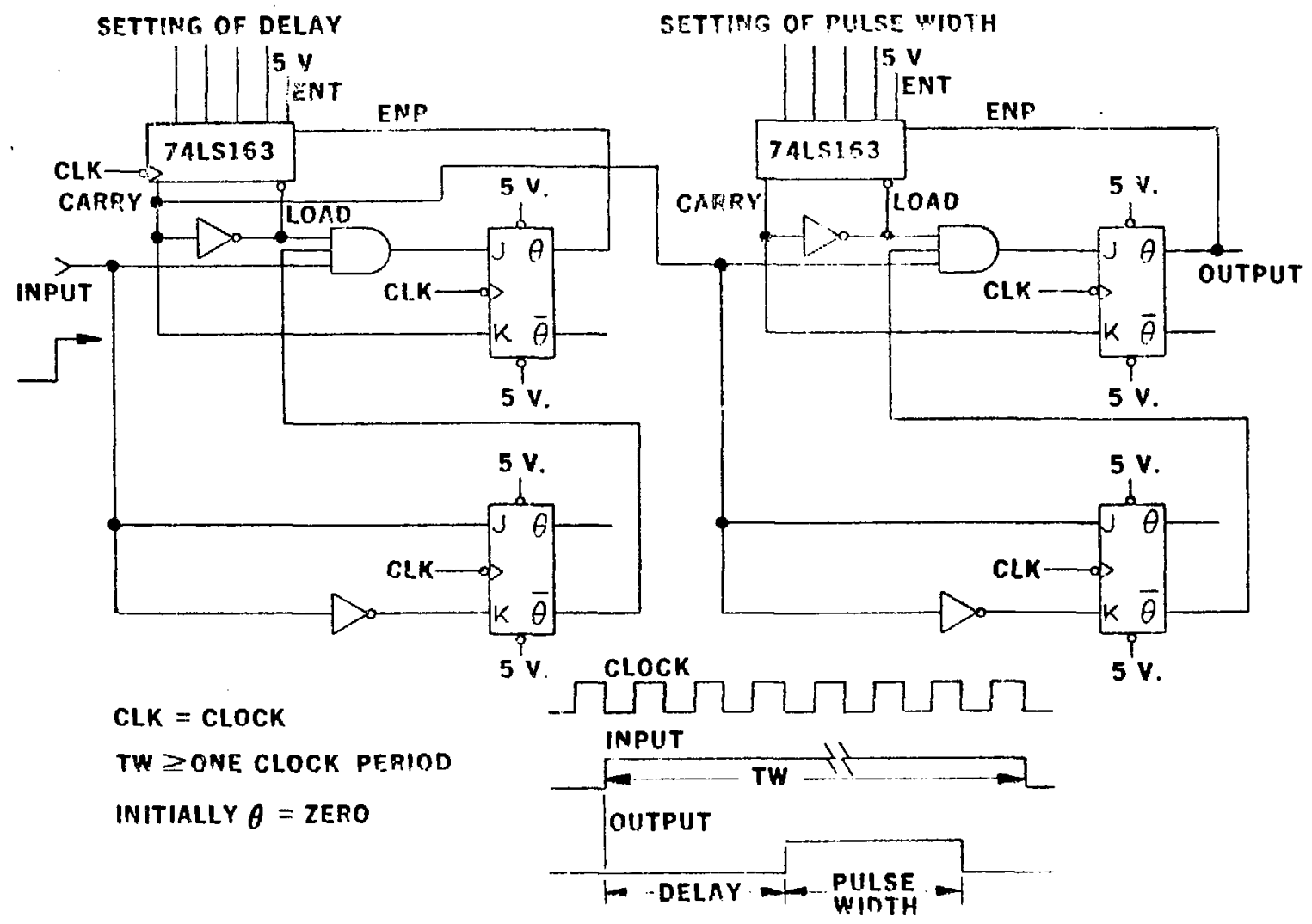




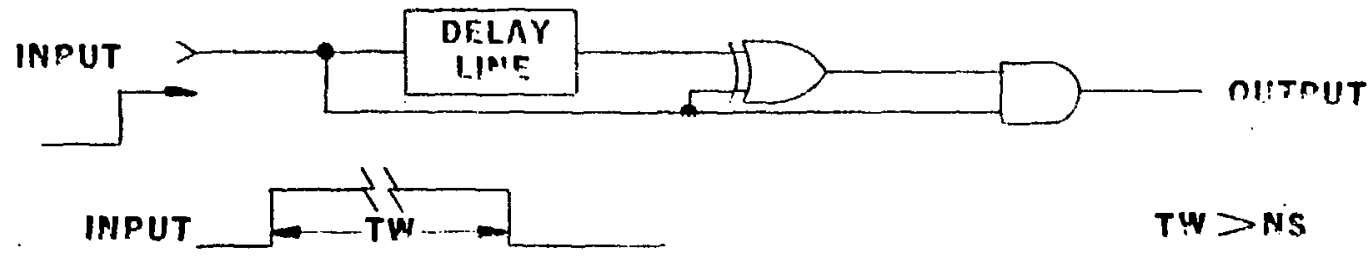

OUTPUT $\rightarrow$ NS _ (OUTPUT PULSF WIDTH DETERMINED RY DELAY LINE)

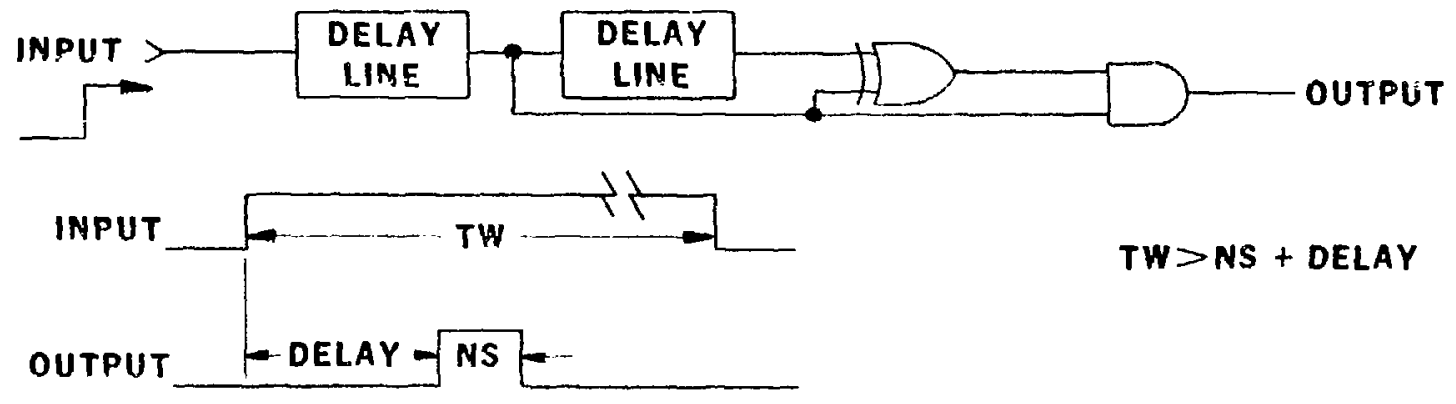

FIGURE - 6: INPUT TRIGGERS AN OUTPUT PULSE OF FIXED PULSE WIDTH AMD DELAY RY DELAY LINES 


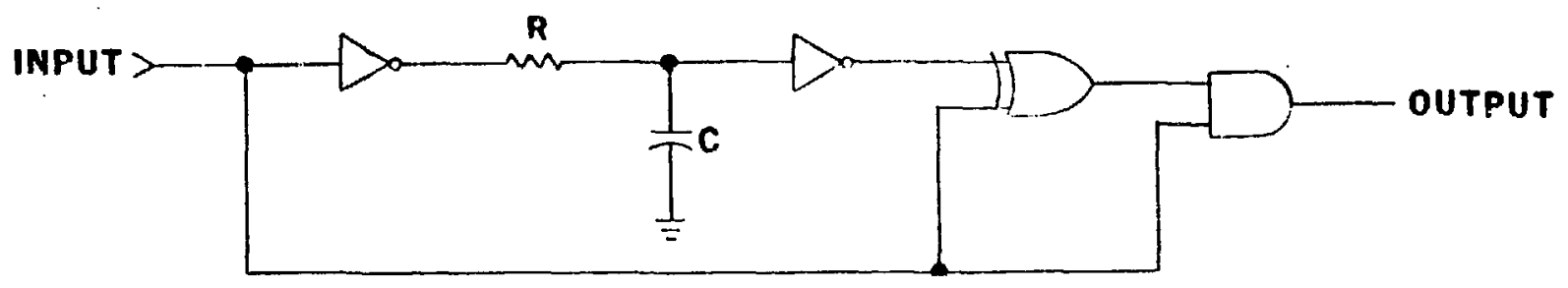

FIGURE - 7: INPUT TRIGGERS AN OUTPUT PULSE (IN NANOSECOND RANGE) 

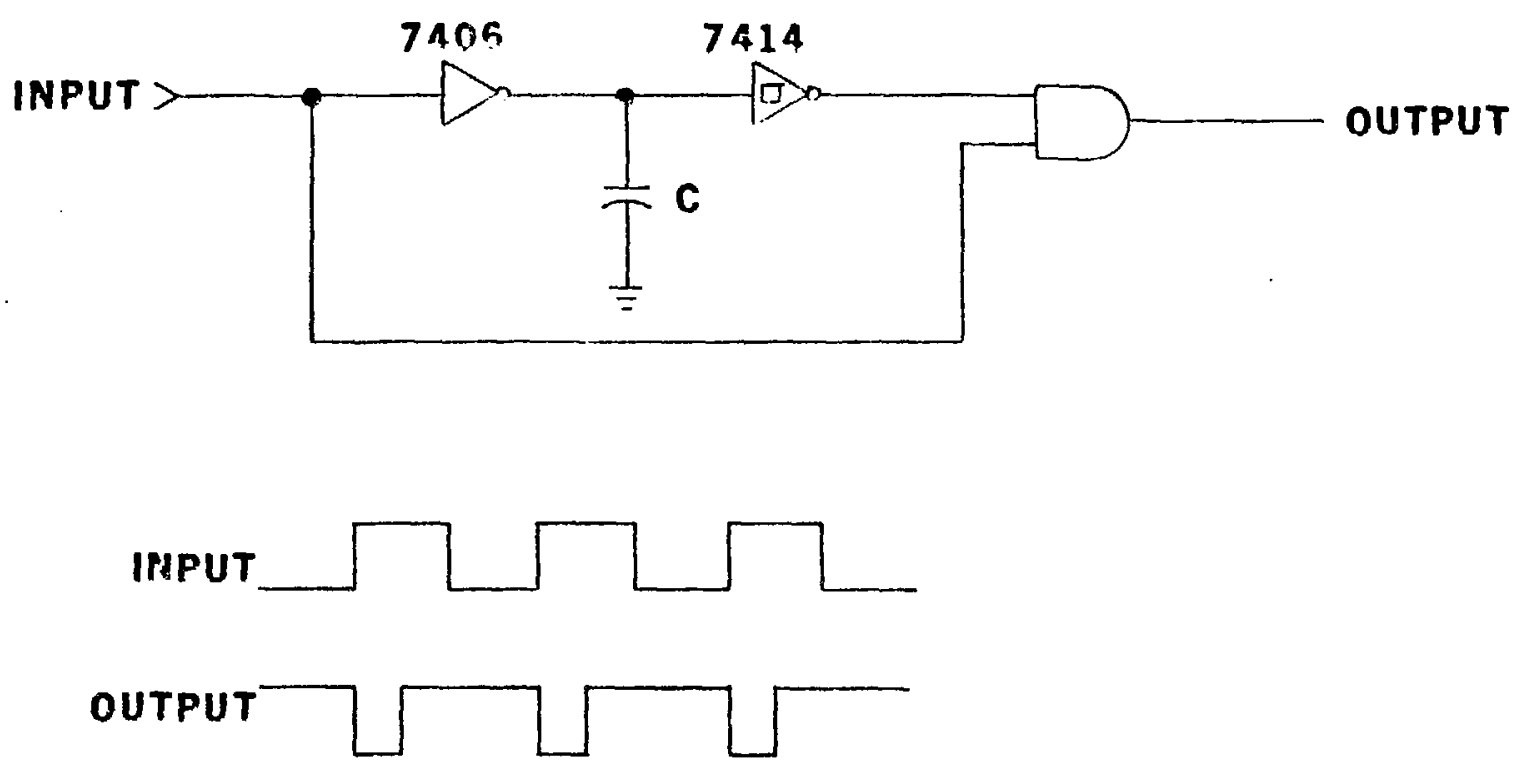


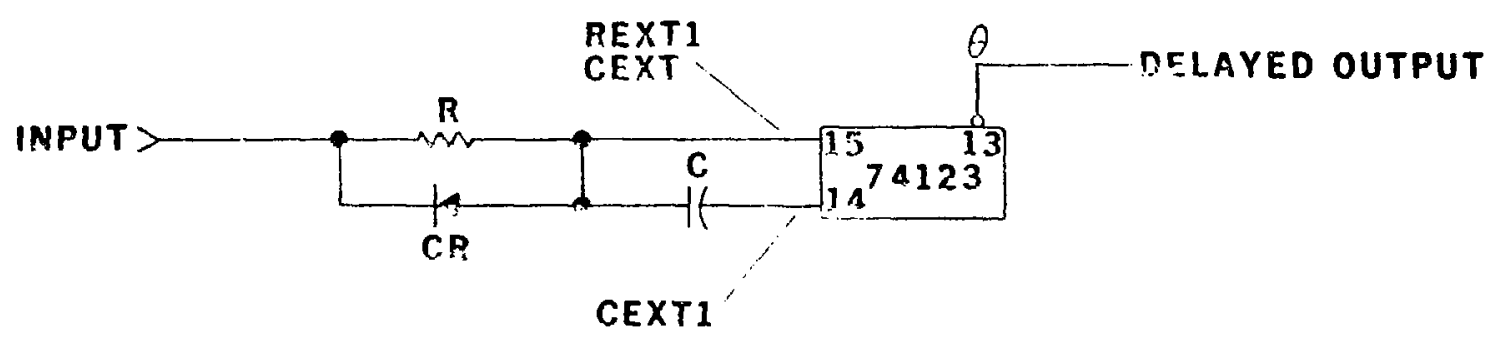

FIGURE - 9: A ONE SHOT IS USED AS A DELAY ELEMENT 